No 3708

Studia nad Autorytaryzmem i Totalitaryzmem 38, nr 1

Wrocław 2016

DOI: $10.19195 / 2300-7249.38 .1 .4$

BARYS LIAPESHKA

Uniwersytet Opolski

\title{
Философия права в Республике Беларусь: в поисках баланса
}

Следует признать: в республике крайне низок интерес к философско-правовой проблематике, фактически отсутствуют работы монографического характера, как в среде юристов, так и философов, исключительно редко защищаются диссертации по проблемам философии права, фактически нет конференций по данной проблематике. Достаточно сказать, что ни на одном юридическом факультете страны, включая Белорусский государственный университет, нет специализированной кафедры философии права.

Причин тому несколько. Первая связана с акцентом на прагматический подход, рассмотрение тех научных проблем, которые связаны с конкретными вопросами становления и развития белорусской государственности. Аспиранты, учёные ориентируются на решение тех правовых проблем, которые связаны с практикой государственного строительства, правовым обеспечением строительства и развития белорусской государственности, различных сфер жизни. Правда, надо сразу же заметить, что взаимосвязь между решениями именно конкретных правовых проблем и общей теорией права прослеживается явно недостаточно, более того, не фиксируется органическая взаимосвязь между пониманием права, типом правопонимания и понятием государства, решением прагматических задач. Другими словами, связь между сугубо теоретическими, концептуальными теориями и решением практических задач правового характера необходимо дополнительно обосновывать.

Вторая причина коренится в различном осмыслении специфики права по сравнению с той традицией, которая сформировалась в рамках западной правовой культуры. Для национальной практики распространённой явилась точка зрения, согласно которой право необходимо трактовать на основе таких, прежде всего, явлений, категорий, как религия, точнее, православный 
выбор, как истины, коренящейся в справедливом, этическом в своей основе выборе приоритетов. Исследователями подчёркивается, что вся восточнославянская традиция основывается на византийской духовной традиции, «в рамках которой право трактовалось как некая стоящая над отдельным человеком и подчиняющая его форма духовного единения на базе правды-справедливости, божественной благодати, христианской этики и т.д.» ${ }^{1}$. А стержнем западной философии права является её человекоцентристская, гуманистическая, по сути, ориентация.

Третья причина носит исторический характер: юридическая наука, кадры суверенной Беларуси активно формировались лишь в послевоенный период, прошло слишком мало времени для того, чтобы сформировались научные школы в этой, достаточно сложной, концептуальной, по сути, сфере правового знания. В этой связи в ходе дальнейшего изложения мы будем обращаться к наработкам, достижениям учёных восточнославянского мира в целом и, прежде всего, российской правовой теории и практике. И первый вопрос в этой связи связан с определением собственно предмета философии права и теми спорами, которые идут в этой сфере среди представителей научной общественности. Остановимся на нескольких точках зрения.

Как полагает, в частности, такой известный специалист, как В.С. Нерсесянц, в настоящее время существует три основных типа правопонимания и, соответственно, три основных философско-правовых концепции. Либертарно-юридический тип правопонимания фиксирует тот факт, что «предмет философии права и государства — это правовой закон и правовое государство» ${ }^{2}$. Формальное равенство и формы его проявления - вот предмет философии права. Легисты делают акцент на принудительно-приказном представлении о праве и, соответственно, в философско-правовой концепции на первое место ставят силу власти. Приоритеты, иерархия предпочтений здесь выстраиваются на основе эмпирических, реальных явлений. Очевидно, что в этой ситуации такие феномены, как ценности, объективная природа права и т.д. уходят на второй план. Юснатуралисты противопоставляют естественное и позитивное право, здесь подлинным правом является лишь право естественное и, в этом контексте, философия права базируется на смешении права с моралью, отсутствии концепции правового закона и т.д. Оценивая дискуссии в сфере правопонимания (и, соответственно, философии права) B.C. Нерсесянц полагает, что недостатки легистского подхода и точки зрения представителей юснатурализма «снимаются» либертарно-юридической концепцией. Суть этого «снятия» в том, что философия права понимается

1 Лапаева В.В. Российская философия права в контексте западной философскоправовой традиции // Вопросы философии. - 2010. - № 5. - С. 4.

${ }^{2}$ Нерсесянц В.С. Философия права: либертарно-юридическая концепция // Вопросы философии. - 2002. - № 3. - С. 11. 
и как сущность, и как явление, то есть, речь идёт о единстве двух сторон: сущности как объективном явлении и законе как явлении, зависимом от субъективного фактора. Право есть форма и мера свободы, реализуемая по принципу формального равенства.

Профессор В.П. Малахов разрабатывает иную теорию, делая акцент на правосознании как исходной категории для понимания природы права и философско-правовой проблематики. Исследование правосознания, по его мнению, позволяет дать теоретическую и прикладную интерпретацию широкому спектру вопросов юридической теории, поскольку в правосознании рассматриваются, главным образом, рефлексирующие способности. Для определения сущности предмета философии права исследователь обращается к трём методологическим установкам: феноменологической, культурологической и диалектической. Причём акцент делается на феноменологические идеи, в рамках которых осуществляется «очищение» и актуализация философско-правовой проблематики ${ }^{3}$. Вместе с тем, как полагают комментаторы, «определяющим для характеристики отечественной правовой культуры является доминирование нравственного и религиозного компонентов социально-духовной жизни российского общества» ${ }^{4}$. Известная точка зрения, «возвращающая» нас к доминантным идеям отечественной философии права, разрабатываемой с середины 19 века.

Близкую позицию отстаивает в рамках коммуникативной теории профессор Санкт-Петербургского университета А.В. Поляков, который призывает к новому синкретизму и новому «всеединству». Сущность представленной точки зрения заключается в том, что признаются эвристически ценными все представленные к нынешнему времени концептуальные воззрения. Так, заслуга юснатурализма в том, что неизбежна связь права с некими идеальными, ценностными началами. Правы и представители социологического подхода, утверждающие важность социальной природы права. Правовая действительность всегда опосредуется правовым сознанием, субъектом и потому так важны достижения адептов психологической школы. Однако все эти достижения имеют смысл тогда, когда за всеми данными процессами стоит человек, находящийся в процессе коммуникации, выступающий как субъект коммуникации. Разрабатывая курс философии права, А.В. Поляков концентрирует внимание на таких проблемах, как типы правопонимания, правовая онтология и аксиология, правосознание и правовая культура, пространство правовой коммуникации, правовой идеал, правовая антропология

${ }^{3}$ Малахов В.П. Концепция философии права // В.П. Малахов. — Москва, 2007. — 751 стр.

${ }^{4}$ Каламкарян Р.А. Концепция философии права // Государство и право. — 2008. — № 3. C. 116 . 
и т.д. ${ }^{5}$. Анализ идей коммуникативной теории в целом, её философско-правовых основ, в частности осуществлён рядом белорусских авторов ${ }^{6}$.

Тот факт, что единства в понимании предмета философии права нет, не должен выглядеть шокирующим. Последний по времени Всемирный конгресс Международной ассоциации философии права, проходивший в Швеции, продемонстрировал, что ведущие тенденции в юридической теории не остаются без изменений даже относительно короткий исторический период, в связи с чем на первый план выходит терпимость и стремление понять друг друга. Единую линию в юриспруденции относительно философии права вычленить сложно. Традиционно основной здесь выступает проблема основания и легитимации права. Выступая на конгрессе с докладом «Природа правовой философии» немецкий учёный Р. Алекси обратил внимание на то, что философия права неразрывно связана с философией. Вопросы: «что должно быть сделано и что есть добро», «что мы можем знать о том и другом» - это проблемы одновременно философские (гносеологические, аксиологические), этические, политические, правовые. Вместе с тем необходимо утверждать автономию философии права. Р. Алекси сформулировал четыре основных принципа философии права: 1) все проблемы общей философии могут возникнуть в философии права; 2) существуют проблемы философии права, происходящие из специфического понимания права; 3) существуют особые отношения философии права с политической и моральной философией; 4) философия права тогда будет эффективной, когда будет основана на всех вышеназванных трёх уровнях ${ }^{7}$.

Следует особо остановиться в этом контексте на проблеме этизации права, столь популярной в отечественной философско-правовой мысли. Привычные для западного стиля мышления апелляции к рационализму не встречали понимания у адептов, прежде всего, православной версии христианской духовной традиции. Отношение к данной точке зрения может быть апологетическим или критическим. В качестве последней представляет интерес позиция профессора В.В. Лапаевой. Характерное для отечественной

5 Поляков А.В., Тимошина Е.В. Общая теория права // А.В. Поляков, Е.В. Тимошина. Санкт-Петербург, 2005. - 472 стр.

6 См., напр.: Лепешко А.Б. Понятийно-категориальный аппарат в феноменологокоммуникативном подходе к анализу социально-правовой действительности / А.Б. Лепешко // Веснік Брэсцкага дзяржаўнага Універсітэта. - сер. 2, Гісторыя, Эканоміка, Права. — 2013. - № 1. - С. 178-186; Лепешко А.Б. Герменевтический метод познания в методологии юриспруденции / А.Б. Лепешко // Право.by. - 2014. - № 3. - С. 11-16; Лепешко А.Б. Феноменолого-коммуникативный подход в праве: эвристические возможности и преимущества / А.Б. Лепешко // Вучоныя запіскі Брэсцкага універсітэта зборнік навуковых прац, вып. 9, ч. 1. Гуманітарныя і грамадскія навукі. - Брэст, 2013. - С. 35-41 и др.

7 Цитата по: Максимов С.И. Современный философско-правовой дискурс: 21 Bсемирный конгресс Международной ассоциации философии права и социальной философии // Правоведение. — 2-3 [год?]. — № 6. - С. 197. 
философии права представление о достижении всеобщей солидарности на основе нравственности, самоограничении индивидуальной свободы ради общего блага свидетельствует о «непонимании (a, скорее, психологическом неприятии) того факта, что общечеловеческая солидарность может утверждаться лишь на основе и в границах формального правового равенства» 8 . Критика различных вариантов отечественного понимания приоритета нравственности над формальным равенством общеизвестна, но вопрос заключается не в том, насколько ущербны такие варианты, а в том, могут ли они безболезненно быть заменёнными иными (западными, рационалистическими в своей основе) оценками и положениями. Даже тот факт, что в советское время одни нравственные оценки были трансформированы в иные (скажем, христианский моральный кодекс принял форму морального кодекса строителя коммунизма) вряд ли свидетельствует исключительно о релятивизме этической концепции права. Можно ведь утверждать не столько релятивные, сколько органичные, консервативные, глубинные истоки сложившегося положения вещей. И здесь, на наш взгляд, необходимо различать несколько уровней понимания проблемы. Первый уровень связан с иным (в отличие от западного) пониманием основополагающих ценностей. Вместо утилитарного подхода - «всемирность» (вспомним известные речи Ф. Достоевского на юбилее А. Пушкина). Вместо «внешней правды», часто отождествляемой с законом, «правда внутренняя» (истина, справедливость). Вместо упорядочения отношений в обществе сегодня и сейчас - апелляция к высшей правде, к осуществлению неких «космических» задач в ближайшем и более отдалённом будущем. Вопрос здесь не в том, насколько утопичны такого рода стремления, а в том, почему именно они являются господствующими в общественном сознании, спроецированные на основные константы философии права. Вряд ли здесь можно ограничиться ссылками на «проклятие русского ума» (формула Э.Ю. Соловьёва). Скажем, почему сегодня, в области решения тех или иных задач, связанных с государственным строительством в Республике Беларусь вызывают в целом положительный резонанс общества те решения властей, которые направлены на «опережение» права. В смысле - решение злободневных проблем вне правового контекста или же решение проблемы сегодня, с тем, чтобы закрепить это решение правовыми средствами завтра. Скажем, на пресс-конференции представителю власти задаётся вопрос, связанный с административным процессом против ряда граждан, по тому или иному поводу. Утром следующего дня административный процесс прекращён, то есть, вопрос признан справедливым и решение последовало незамедлительно. С точки зрения традиции, сложившейся на Западе, это неправомерный ход событий. С точки зрения отечественной правовой практики всё закономерно. Связано это, во-первых,

8 Лапаева В.В. Российская философия права ..., с. 5-6. 
с отсутствием в восточнославянском ареале соответствующих условий для существования в правовом поле, исторически поздним временем реализации «внешних» (читай: правовых) форм существования. Во-вторых, говоря языком метафизики, надежда на истину и справедливость у нас всегда выше надежды на правовое решение проблемы. В начале «царь», а уже затем «суд», собственно, эти понятия во многом рассматриваются как синонимы. Показательно, как во время трагических событий 2015 года в Хакасии (Российская Федерация), связанных с пожарами, народ, пострадавший от огня, ждал президента страны. Ждал не решения своих проблем в соответствии с действующим законодательством, а ждал приезда руководителя страны. «Бояре» могут обмануть, «царь» - никогда. Возможно, подобные тенденции будут преодолены в будущем, во всяком случае, в последнем (2015 года) Послании президента Республики Беларусь белорусскому народу среди первоочередных задач сформирована задача воспитания правовой культуры во всех сферах жизни и, прежде всего, экономики. В-третьих, нельзя думать, что отказ (сегодня, сейчас) от приоритета этических констант по отношению к константам сугубо правовым будет иметь успех в части не «этического», а «правового» развития страны. Достаточно вспомнить призывы к демократии, которые слышались, начиная с 90-х годов и сравнить либеральное умственное движение конца прошлого века с сегодняшними политико-правовыми реалиями, чтобы понять: ситуация вдруг не изменится. Более того, изменить ситуацию можно, опираясь на ту реальность, которая имеет место у нас сегодня и сейчас. Ведь авторитет Ф. Достоевского, Л. Толстого, Вл. Соловьёва, В. Розанова, Дм. Мережковского и многих иных мыслителей первого ряда столь велик и глубок, что надеяться каким бы то ни было образом искусственно «уйти» от заявленных ими идей вряд ли возможно. Скорее, надо искать варианты сосуществования различных модификаций «русской идеи» (в их классическом виде) с необходимостью реализации принципа формального равенства, свободы, ответственности. Далеко не случайно в этой связи столь распространены сегодня различные варианты интегративного правопонимания, коренящиеся как в западной, так и в отечественной правовой традиции.

Если говорить о философии права в контексте развития белорусской философско-правовой мысли, то необходимо акцентировать внимание на следующих основных моментах. Первое - это понимание связи, зависимости философии права от развития философского знания в целом. Здесь, надо признать, существуют различные подходы и умозрения. Назовём лишь два. Один, условно говоря, «чаадаевский», связан с пониманием неразвитости отечественной философской традиции в целом, философско-правовой в частности. Сторонники этой позиции утверждают, что нам сложно назвать имена и идеи, которые составили бы эпоху в развития европейского, мирового философского знания, причём это относится как к исторической 
традиции, так и современным реалиям. Есть и второй подход, где говорится о разработке ряда важнейших идей философского знания (косвенно философии права) и здесь адепты этой точки зрения апеллируют к именам К. Лыщинского, Луки Залусского, Льва Сапеги, Георгия Конисского и так далее. В данном случае сопоставление этих альтернативных точек зрения и соответствующая дискуссия представляется не ко времени, однако важно заметить, что к реальному «выходу» в философию права и соответствующей проблематике эти достижения (с точки зрения представителей второй тенденции) не привели. Можно говорить о начатках «схоластического аристотелизма» $^{9}$, но сложно говорить о предмете философии права и основных категориях данной сферы правового знания.

Второе - пытаясь определить национальные особенности белорусской философии права, мы неизбежно приходим к выводу о том, что они определяются отношением к западной философско-правовой мысли и русской философско-правовой мысли. Восприятие важнейших философско-правовых идей как с одной стороны, так и со стороны другой сложно представить без общеполитического, мировоззренческого, философского, ментального контекста развития национальной культуры. В самом общем виде этот процесс можно охарактеризовать в следующих положениях: доминирование государства над иными социальными институтами; долгие годы абсолютистской власти; внешние угрозы и междоусобицы; возможность выживания в рамках общины, общинной культуры и второстепенность проблемы свободы в целом, свободы личности, в частности в рамках формирования правового идеала. Нельзя утверждать, что в результате этого процесса можно и нужно говорить об абсолютной победе той или иной точки зрения. Скорее, культуры сталкивались «над» народом, озабоченным выживанием. Важно и иное: диалога культур, о котором можно было только мечтать, не получилось. То есть, нельзя утверждать, что западная и восточная культура в результате взаимодействия, часто конфронтационного, дали жизнь некоему новому, третьему культурному образованию. На наш взгляд, произошло иное: ростки белорусской национальной культуры фактически «затаптывались», элиты тяготели либо к одному, либо к иному культурному образованию, а в результате проигрывал белорусский народ. И, если русская культура пережила ренессанс второй половины 19-начала 20 века, названный Серебряным веком русской культуры, если польская культура сумела подняться к передовым позициям развития западной науки, то о развитии белорусской национальной философии, философии права мы можем говорить как о периоде ученичества.

9 Памятники философской мысли Белоруссии 17-первой половины 18 века // В.В. Дубровский и др. - Минск, 1991. — С. 16. 
Третье: при всех, часто взаимоисключающих влияниях западной и восточной культур оказался приоритетным тот выбор, который связывался с развитием единых духовных констант в контексте восточнославянского развития. Сложно говорить о проявлении этих констант в философии права, поскольку в «чистом» виде работ такого порядка просто нет. Но очевидна общая система ценностей: выдвижение на первый план этической проблематики; приоритет нравственного чувства; цельность знания, однако, в рамках религиозного опыта; гуманистический потенциал, связанный с категориями справедливости, правды, истины. Присутствовал философский путь к Богу, причём этот путь был, по преимуществу, православным. Были и отличия. В частности, в белорусской культуре не найдётся работ, в которых осмысливался бы некий особый путь развития страны, констатировалась особая роль народа в историческом процессе. Если и можно назвать белорусов «метафизическим» народом, то только в смысле приоритета этических идеалов над формально-догматическими и меркантильными.

Подытоживая сказанное, можно утверждать, что проблема баланса (идей, теорий, подходов) в философско-правовом процессе для белорусской философской и правовой мысли остаётся приоритетной. Причём эта задача не меняется в своих существенных чертах последние несколько столетий. Можно тысячу раз произносить правильные слова о важности формирования правовой культуры, правового общения (коммуникации), но всё это второстепенные проблемы по отношению к решению задачи основной. Эта задача - развитие общего культурного пространства страны, формирование элит, в том числе тех её представителей, кто посчитает важным и первоочередным обратиться к важнейшим общетеоретическим правовым проблемам, философско-правовым проблемам, в частности.

\section{Библиография}

Алексеев С.С. Основы философии права // С.С. Алексеев - СПБ: Лань, 1999. - 256 стр.

Алексеев С.С. Философия права: история и современность // С.С. Алексеев. - М.: Норма, 1999. - 312 стр.

Берман Г.-Дж. Западная традиция права: эпоха формирования // Г.-Дж. Берман. - М.: МГУ, 2008. - 464 стр.

Каламкарян Р.А. Концепция философии права // Государство и право. — 2008. - № 3. - C. 115-118. Калинин С.А. Методология общей теории права /С.А. Калинин // Право. — 2011. — № 2. — С. 7-17.

Калинин С.А. О методологии изложения сущности права / С.А. Калинин // Право и политика. - 2003. - № 11. - C. 4-12.

Лапаева В.В. Российская философия права в контексте западной философско-правовой традиции // Вопросы философии. - 2010. - № 5. - С. 3-14.

Лепешко А.Б. Герменевтический метод познания в методологии юриспруденции / А.Б. Лепешко // Право.by. — 2014. — № 3. - С. 11-16.

Лепешко А.Б. Понятийно-категориальный аппарат в феноменолого-коммуникативном подходе к анализу социально-правовой действительности / А.Б. Лепешко // Веснік Брэсцкага 
дзяржаўнага Універсітэта. - сер. 2, Гісторыя, Эканоміка, Права. - 2013. - №1. C. $178-186$.

Лепешко А.Б. Феноменолого-коммуникативный подход в праве: эвристические возможности и преимущества / А.Б. Лепешко // Вучоныя запіскі Брэсцкага універсітэта зборнік навуковых прац, вып. 9, ч. 1. Гуманітарныя і грамадскія навукі. - Брэст, 2013. - С. 35-41.

Максимов С.И. Современный философско-правовой дискурс: 21 Всемирный конгресс Международной ассоциации философии права и социальной философии // Правоведение. № 6. - С. 194-201.

Малахов В.П. Концепция философии права // В.П. Малахов. - М.: ЮНИТИ-ДАНА, 2007. 751 стр.

Малинова И.П. Философия права и юридическая герменевтика // И.П. Малинова. — M: Норма, 2014. - 176 стр.

Нерсесянц В.С. Философия права: либертарно-юридическая концепция // Вопросы философии. - 2002. - № 3. - С. 3-15.

Новгородцев П.И. Введение в философию права // П.И. Новгородцев. — СПБ: 2000. - 352 стр. Поляков А.В., Тимошина Е.В. Общая теория права //А.В. Поляков, Е.В. Тимошина. - Издво СПБ университета, 2005. - 472 стр.

\section{THE PHILOSOPHY OF LAW IN THE BELARUSSIAN REPUBLIC - IN SEARCH OF A BALANCE}

\section{Summary}

The philosophical and legal studies in the Republic of Belarus are analyzed in the article. The point of view that the tradition of studying of philosophy of law in the Western Europe and in the post-Soviet countries differ greatly is expressed and proved. Attention is drawn to the subject matter of philosophy of law and its principles; controversial aspects of this segment of philosophical and legal knowledge are analyzed. The connection between philosophical and legal problems with the objectives of accomplishment of legal culture is presented. Philosophical and legal issues, which are relevant and described in the works of Belarusian and Russian scientists are studied.

Keywords: philosophy of law, theory of law, Belarus, post-Soviet country, post-totalitarian country.

\section{ФИЛОСОФИЯ ПРАВА В РЕСПУБЛИКЕ БЕЛАРУСЬ: В ПОИСКАХ БАЛАНСА}

В статье проанализировано состояние философско-правовых исследований в Республике Беларусь. Высказана и обоснована точка зрения, согласно которой традиции изучения философии права в Западной Европе и на постсоветском пространстве существенно отличаются. Обращено внимание на понимание предмета философии права, её принципов, проанализированы дискуссионные аспекты этого сегмента философского и правового знания. Показана связь философско-правовых проблем с задачами воспитания правовой культуры. Исследована философско-правовая проблематика, являющаяся актуальной и изложенная в трудах белорусских и российских учёных.

Ключевые слова: философия права, теория права, постсоветское общество, методология права.

Barys Liapeshka

e-mail: borys_lepieszko@tut.by

Studia nad Autorytaryzmem i Totalitaryzmem 38, nr 1, 2016

(C) for this edition by CNS 